Thorax, 1980, 35, 873-876

\title{
Domiciliary nebulised salbutamol solution in severe chronic airway obstruction
}

\author{
R S E WILSON AND S J CONNELLAN
}

From the Department of Respiratory Medicine, Royal Shrewsbury Hospital, Shrewsbury

ABSTRACT Nine patients with severe chronic airway obstruction secondary to chronic bronchitis and emphysema all preferred nebulised salbutamol solution to placebo in a double-blind controlled trial. Four of the patients who had previously received domiciliary nebulised salbutamol failed to complete the placebo period, though all completed the active period. Five others improved subjectively on active therapy, and showed a significant improvement in morning and evening peak flows. Symptom scores for breathlessness, wheezing, and sputum production were lower in the active treatment period and standard aerosol usage fell, although these changes might have been due to chance. Patients with severe chronic airway obstruction who do not respond to conventional bronchodilator therapy should be considered for this form of treatment.

Chronic bronchitis and emphysema affect about one million people in the United Kingdom. The major aetiological factor in both conditions is cigarette smoking, although it is not known why one smoker develops predominant chronic bronchitis while another develops predominant emphysema. In widespread severe emphysema the respiratory drive is well maintained, the oxygen saturation is near normal at rest, and the patient becomes a typical "pink puffer". He suffers from unrelenting breathlessness-often so severe that he has difficulty in eating, washing, or dressing. The treatment of this condition is disappointing for both patient and doctor. There is little or no response to corticosteroids, or to oral and inhaled bronchodilators.

Recently, in an uncontrolled trial, patients claimed considerable relief from regular nebulised salbutamol solution given at home. ${ }^{1}$ We decided to extend this study to a double-blind controlled trial using an inert placebo solution versus salbutamol solution in the patient's home.

\section{Methods}

In the study, double-blind and cross-over in design, each patient was studied for four weeks, two weeks on inert placebo solution via a nebuliser $(2 \mathrm{ml}$ four times daily) and two weeks on a mixture of $1 \mathrm{ml}$

Address for reprint requests: Dr RSE Wilson, Department of Respiratory Medicine, Royal Shrewsbury Hospital, Shrewsbury, Shropshire.
( $5 \mathrm{mg}$ ) salbutamol respirator solution plus $1 \mathrm{ml}$ of sterile water ( $2 \mathrm{ml}$ four times daily). The nebuliser was driven by an electric air compressor. The order of each medication period was predetermined by random selection. Both solutions were identical in appearance and were packed in identical containers. Each patient was also given a standard active salbutamol aerosol inhaler for intermittent emergency use only and the number of times this was used was recorded daily.

Nine male and one female patient, age range 47-81 years, were studied. All had severe chronic airway obstruction with marked dyspnoea. They had all been given a high dose corticosteroid trial with little or no subjective or objective benefit. Nine patients were ex-smokers, and one continued to smoke "three cigarettes daily".

Eight patients had chronic bronchitis. ${ }^{2}$ Nine patients showed radiological evidence of emphysema with low flat diaphragms, a large retrosternal airspace, and pruning of the peripheral vessels. $^{3}$ All had large total lung capacities and reduced transfer factors.

Three patients continued on $5 \mathrm{mg}$ prednisone daily, while seven received no other medication for their airway obstruction other than the emergency aerosol supplied.

Before the study, peak expiratory flow (PEF) was measured on a Wright's peak flow meter, forced expiratory volume in one second $\left(\mathrm{FEV}_{1}\right)$ and vital capacity (VC) were measured on a dry bellows spirometer. Total lung capacity was 
measured by the helium dilution method, and carbon monoxide transfer factor by the single breath technique. ${ }^{4}$.

In six patients a 12-minute walk test was carried out on a treadmill. This was performed after 200 $\mu \mathrm{g}$ of salbutamol was given by aerosol, and again after $5 \mathrm{mg}$ of nebulised salbutamol solution. The treadmill was set at a comfortable walking speed for each individual (usually $2 \mathrm{kph}$ ) without any incline. The patients were asked to walk until they reached the point at which they would usually stop for a breather. It was stressed that they should not push themselves past this mark. Distances walked and the number of stops were noted over a period of 12 minutes. The patient's electrocardiogram and heart rate were monitored throughout.

Each patient was supplied with a daily diary booklet and the following observations were noted for day (0700-1900) and night (1900-0700): severity of wheeze, cough, sputum, sleeplessness, sideeffects, and the number of times the emergency salbutamol aerosol inhaler was used. Peak expiratory flow rate was recorded morning and evening -three attempts were made at each time of day 30 minutes after nebuliser therapy and the best reading in the morning and evening has beenc assessed.

Any patient unable to complete the first period $\overrightarrow{\widetilde{\alpha}}$ of the trial informed an investigator who, having $\frac{\varrho}{0}$ broken the code, decided whether the patient ${ }^{\text {s }}$ should continue on the second period.

\section{Results}

Of the 10 patients in the study, one was with- $x$ drawn because of mechanical failure in the airo compressor. Four other patients withdrew during $\overrightarrow{-}$ the placebo period because of an increase in symptoms (two during the first two weeks and twow during the second). Those who withdrew in the 은 first two weeks were then asked to change to the second two weeks of treatment, and were able to $z$ complete this period. These four patients had $\underset{\Phi}{ }$ received regular nebulised salbutamol at home 3 for several months before the trial.

Five patients, none of whom had previously $\vec{\oplus}$ received nebulised salbutamol, completed the trialo and these were further assessed.

Physiological data are shown in table 1. Allo patients had an $\mathrm{FEV}_{1}$ of less than 1 1. there was little improvement in PEF or $\mathrm{FEV}_{1}$ after bron-O

Table 1 Physiological data

\begin{tabular}{|c|c|c|c|c|c|c|c|c|c|c|c|c|c|}
\hline \multirow{2}{*}{$\begin{array}{l}\text { Patient } \\
\text { number }\end{array}$} & \multicolumn{3}{|c|}{ Peak flow rate (l/min) } & \multicolumn{3}{|c|}{$F E V_{1}(l)$} & \multicolumn{3}{|c|}{ Vital capacity $(l)$} & \multirow{2}{*}{$\begin{array}{l}\text { Total lung } \\
\text { capacity } \\
\%\end{array}$} & \multirow{2}{*}{$\begin{array}{l}\text { Transfer } \\
\text { factor } \\
\text { predicted }^{5}\end{array}$} & \multicolumn{2}{|c|}{ Walk test (metres) } \\
\hline & $A$ & $\boldsymbol{B}$ & $C$ & $A$ & $\boldsymbol{B}$ & $C$ & $A$ & $B$ & $C$ & & & $B$ & $C$ \\
\hline $\begin{array}{r}1 \\
2 \\
3 \\
4 \\
5 \\
6 \\
7 \\
8 \\
9 \\
10\end{array}$ & $\begin{array}{r}105 \\
125 \\
110 \\
150 \\
120 \\
70 \\
65 \\
165 \\
160 \\
120\end{array}$ & $\begin{array}{r}105 \\
145 \\
110 \\
165 \\
145 \\
75 \\
70 \\
170 \\
170 \\
125\end{array}$ & $\begin{array}{r}125 \\
165 \\
105 \\
175 \\
160 \\
85 \\
85 \\
200 \\
170 \\
135\end{array}$ & $\begin{array}{l}0.80 \\
0.35 \\
0.35 \\
0.8 \\
0.85 \\
0.4 \\
0.45 \\
0.65 \\
0.8 \\
0.65\end{array}$ & $\begin{array}{l}0.80 \\
0.45 \\
0.35 \\
0.9 \\
1.05 \\
0.5 \\
0.45 \\
0.70 \\
0.9 \\
0.7\end{array}$ & $\begin{array}{l}1.00 \\
0.55 \\
0.35 \\
1.00 \\
1.10 \\
0.65 \\
0.5 \\
0.80 \\
1.00 \\
0.8\end{array}$ & $\begin{array}{l}2 \cdot 65 \\
1 \cdot 9 \\
1 \cdot 55 \\
2 \cdot 3 \\
2 \cdot 2 \\
1 \cdot 9 \\
1 \cdot 65 \\
2 \cdot 0 \\
1 \cdot 75 \\
1 \cdot 75\end{array}$ & $\begin{array}{l}2 \cdot 70 \\
1 \cdot 95 \\
1 \cdot 70 \\
2 \cdot 3 \\
2 \cdot 75 \\
2 \cdot 0 \\
1 \cdot 7 \\
2 \cdot 3 \\
1 \cdot 8 \\
1.9\end{array}$ & $\begin{array}{l}2 \cdot 75 \\
2 \cdot 65 \\
1 \cdot 50 \\
2 \cdot 5 \\
2 \cdot 65 \\
2 \cdot 1 \\
1 \cdot 85 \\
2.55 \\
1.9 \\
2 \cdot 25\end{array}$ & $\begin{array}{l}142 \\
130 \\
-131 \\
115 \\
119 \\
118 \\
124 \\
115 \\
130\end{array}$ & $\begin{array}{r}23 \\
21 \\
32 \\
35 \\
33 \\
6 \\
42 \\
13 \\
8\end{array}$ & $\begin{array}{r}127 \\
481 \\
96 \\
305 \\
- \\
- \\
\overline{300} \\
\overline{256}\end{array}$ & $\begin{array}{l}250 \\
532 \\
117 \\
332 \\
- \\
- \\
\overline{400} \\
\overline{290}\end{array}$ \\
\hline Mean & $119^{\circ}$ & 128 & 140 & 0.62 & 0.68 & 0.83 & 1.97 & $2 \cdot 11$ & $2 \cdot 27$ & 125 & $23 \cdot 5$ & 261 & 320 \\
\hline
\end{tabular}

Table 2 Peak flow rates (mean over both 14-day treatment periods)

\begin{tabular}{|c|c|c|c|c|c|c|}
\hline \multirow[t]{2}{*}{ Patient number } & \multicolumn{2}{|c|}{ Placebo period } & \multicolumn{2}{|c|}{ Salbutamol period } & \multicolumn{2}{|l|}{ Change } \\
\hline & Morning & Evening & Morning & Evening & Morning & Evening \\
\hline $\begin{array}{r}5 \\
7 \\
8 \\
9 \\
10\end{array}$ & $\begin{array}{r}90 \\
133 \\
209 \\
221 \\
129\end{array}$ & $\begin{array}{r}91 \\
115 \\
187 \\
227 \\
132\end{array}$ & $\begin{array}{l}135 \\
180 \\
254 \\
247 \\
179\end{array}$ & $\begin{array}{l}174 \\
161 \\
247 \\
237 \\
184\end{array}$ & $\begin{array}{l}+45 \\
+47 \\
+45 \\
+26 \\
+50\end{array}$ & $\begin{array}{l}+83 \\
+46 \\
+60 \\
+10 \\
+52\end{array}$ \\
\hline Mean & 156 & 150 & 199 & 201 & +43 & +50 \\
\hline
\end{tabular}


chodilator. In patient 2 , the VC improved by $700 \mathrm{ml}$ after $5 \mathrm{mg}$ nebulised salbutamol, and patient 5 improved by $550 \mathrm{ml}$ after $200 \mu \mathrm{g}$ of salbutamol by standard aerosol. The changes in VC were otherwise small.

Six patients performed a 12-minute treadmill walk test after $200 \mu \mathrm{g}$ and again after $5 \mathrm{mg}$ of inhaled salbutamol. All were able to walk further after the higher dose.

Table 2 shows the mean PEF for each patient for both treatment periods. The best of three readings taken 30 minutes after treatment in the morning and evening have been used. All attained higher readings during the active treatment period -an average of $+431 / \mathrm{min}$ in the morning and $+501 / \mathrm{min}$ in the evening. Analysis of variance shows these changes to be significant at $p=<0 \cdot 05$.

Symptom scores were recorded according to the following scale: $3=$ severe, 2 or $1=$ average, and $0=$ none. Total scores for breathlessness, wheeze, and sputum production are shown in table 3. The scores for breathlessness, wheeze, and sputum production fell during the active treatment period for both day and night, although these changes were not statistically significant. The scores for cough, sleeplessness, and shakiness showed no difference between the active and placebo period and are not shown in the table.

Emergency aerosol usage is also shown in table 3. The daytime usage during the active period was lower than in the placebo period although this difference was not statistically significant.

At the end of the study all patients were asked to state a preference for either the treatment during the first or second two weeks of the trial. All stated a preference for the active period regardless of the order in which treatments were given.

The four patients who had previously received domiciliary nebulised salbutamol all preferred the active period and were unable to tolerate the placebo period for more than a few days because of an increase in symptoms.
It can be argued that nine out of nine patients showed a preference for active solution. The chance of this being accidental is $(0.5),{ }^{9}$ or rather less than 2 in 1000 . This is, therefore, unlikely to be a chance effect. Even if those who had previously been treated with the drug, and were therefore selected as responders, are excluded, the likelihood of the five others all preferring active drug by chance is $3 \%$.

\section{Discussion}

Severe chronic airflow obstruction can cause distressing breathlessness which is difficult to treat. Radiotherapy may offer some relief in severe emphysema $^{6}$ as may regular nebulised bronchodilator therapy. ${ }^{1}$ However both the treatments require further evaluation.

The patients reported here had had severe breathlessness for several years in spite of treatment with corticosteroids and conventional bronchodilators. All had expressed a feeling of improvement when given nebulised salbutamol respirator solution either as inpatients or outpatients.

In the present study, four patients who had received nebulised salbutamol at home before the study found that symptoms were intolerable during the placebo period and dropped out of the trial, although when this occurred during the first treatment period they were able to complete the second two weeks when they were unknowingly receiving active therapy.

The five patients who completed the trial all preferred the active treatment period. Three volunteered that they were better symptomatically than they had been for some years, and were anxious to continue on nebulised salbutamol. One other patient felt sufficient improvement to continue, but the remaining patient felt that the improvement was not enough to change from his usual treatment of regular salbutamol pressurised aerosol.

Table 3 Symptom scores

\begin{tabular}{|c|c|c|c|c|c|c|c|c|c|c|c|c|c|c|c|c|}
\hline \multirow{3}{*}{$\begin{array}{l}\text { Patient } \\
\text { number }\end{array}$} & \multicolumn{4}{|c|}{ Breathlessness } & \multicolumn{4}{|c|}{ Wheeze } & \multicolumn{4}{|c|}{ Sputum } & \multicolumn{4}{|c|}{ Aerosol usage } \\
\hline & \multicolumn{2}{|c|}{ Placebo } & \multicolumn{2}{|c|}{ Salbutamol } & \multicolumn{2}{|c|}{ Placebo } & \multicolumn{2}{|c|}{ Salbutamol } & \multicolumn{2}{|c|}{ Placebo } & \multicolumn{2}{|c|}{ Salbutamol } & \multicolumn{2}{|c|}{ Placebo } & \multicolumn{2}{|c|}{ Salbutamol } \\
\hline & Day & Night & Day & Night & Day & Night & Day & $\overline{\text { Night }}$ & Day & Night & Day & Night & Day & Night & Day & Night \\
\hline $\begin{array}{r}5 \\
7 \\
8 \\
9 \\
10\end{array}$ & $\begin{array}{l}27 \\
31 \\
17 \\
38 \\
38\end{array}$ & $\begin{array}{l}26 \\
33 \\
16 \\
13 \\
42\end{array}$ & $\begin{array}{l}22 \\
33 \\
14 \\
29 \\
21\end{array}$ & $\begin{array}{l}22 \\
32 \\
14 \\
15 \\
35\end{array}$ & $\begin{array}{l}27 \\
36 \\
28 \\
14 \\
31\end{array}$ & $\begin{array}{l}30 \\
34 \\
28 \\
12 \\
35\end{array}$ & $\begin{array}{r}24 \\
30 \\
28 \\
9 \\
14\end{array}$ & $\begin{array}{r}25 \\
26 \\
28 \\
2 \\
21\end{array}$ & $\begin{array}{r}16 \\
14 \\
14 \\
7 \\
17\end{array}$ & $\begin{array}{r}0 \\
15 \\
14 \\
0 \\
17\end{array}$ & $\begin{array}{r}13 \\
5 \\
14 \\
2 \\
15\end{array}$ & $\begin{array}{r}0 \\
3 \\
14 \\
0 \\
14\end{array}$ & $\begin{array}{r}56 \\
20 \\
0 \\
85 \\
36\end{array}$ & $\begin{array}{r}0 \\
9 \\
0 \\
2 \\
13\end{array}$ & $\begin{array}{r}48 \\
17 \\
0 \\
78 \\
1\end{array}$ & $\begin{array}{l}0 \\
8 \\
0 \\
7 \\
0\end{array}$ \\
\hline Mean & $30 \cdot 2$ & 26 & $23 \cdot 8$ & $23 \cdot 6$ & $27 \cdot 2$ & $27 \cdot 8$ & 21 & $20 \cdot 4$ & $13 \cdot 6$ & $9 \cdot 2$ & $9 \cdot 8$ & $6 \cdot 2$ & $39 \cdot 2$ & $4 \cdot 8$ & $28 \cdot 8$ & 3 \\
\hline
\end{tabular}


There seems little doubt that nebulised salbutamol given regularly at home can improve the quality of life in patients with "irreversible" airway obstruction though this is not invariable. It is not clear how to assess which patients might benefit. In those studied here it was not always possible, using the usual indications of bronchodilator response (PEF, FEV, or VC) to predict those who would benefit. In six patients who performed a walk test all showed an increased walking distance even in the absence of an obvious bronchodilator response, and this may be a useful addition to patient assessment. It is also of interest that even patients who showed little or no improvement in PEF in the respiratory laboratory showed considerable improvement in both morning and evening PEF during active treatment at home.

The apparatus for establishing domiciliary therapy is not available on prescription and has to be supplied by the hospital or the patient. There are several suitable nebuliser units available, and these have been reviewed recently. ${ }^{7}$ It is important for efficiency that they are matched with the appropriate driving source. The domiciliary oxygen flow head gives a maximum flow rate of $4 \mathrm{l} / \mathrm{min}$. This is not suitable for any of the available nebuliser units. Furthermore the 13601 oxygen cylinder is sufficient for only 20 treatment periods, would cost over $£ 500$ per year, requires delivery to the patient's home, and is cumbersome. The most suitable driving source is a portable electric compressor. Those available are generally robust, reliable, and work at an acceptable noise level. The price varies between about $£ 47$ and $£ 110$.

We suggest that patients with severe irreversibled airway obstruction should be considered for regu lar nebulised salbutamol, and that measurement ${ }^{n}$ of peak flow at home during treatment or a walk을 test are the best objective measurements in assessing which patient is likely to benefit.

We are grateful to Allen and Hanbury's Ltd for their help in the preparation of this trial, to Mrer $\mathbf{R}$ Steventon for technical help, and to Dr WEWake for assistance with the statistical analysis.

References

1 Connellan SJ, Wilson RSE. The use of domiciliary nebulised salbutamol in the treatment of severe emphysema. Br J Clin Pract 1979; 33:135-6.

2 Medical Research Council. Definition and classification of chronic bronchitis for clinical and epidemiological purposes. Lancet 1965; 1:776.

3 Simon G. Principles of chest x-ray diagnosis. Third edition. London: Butterworth, 1971:142-58.

4 Ogilvie CM, Forster RE, Blackmore WS, Morton JW. A standardised breath holding technique for clinical measurement of the diffusing capacity of

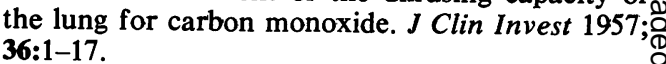

5 Cotes JE. Lung function. Third edition. Oxford: Blackwell, 1975 .

6 Axford AT, Cotes JE, Deeleys TJ, Smith CW. Clinical improvement of patients with emphysemao after radiotherapy. Thorax 1977; 32:35-9.

7 Steventon RD, Wilson RSE. Nebuliser units. $B r$ J Clin Equip 1979; 153-6. 